Thrombotic complications in acute polyneuritis

SIR,-We would like to add our concern to that of Dr E Jane Leese (6 March, p 585), at the high incidence of deep venous thrombosis in acute polyneuritis despite regular physiotherapy.

Twenty-two patients with respiratory muscle weakness due to acute polyneuritis were referred to this unit from the South Wales region during 1967-75, 17 of whom, in the event, required assisted ventilation. Six patients, half of whom were ventilated, had thromboembolic complications. Three of these developed venous thrombosis without embolism and two had pulmonary embolism without clinical evidence of venous thrombosis. All these five patients recovered; four were treated with conventional anticoagulants and one, who had a history of peptic ulcer, was treated with dextran 40 . The sixth patient, a 65-year-old woman, who did not require ventilation, died eight days after her return to her base hospital, having developed deep venous thrombosis of the left leg complicated by pulmonary embolism; she was not treated with anticoagulants.

Our own experience leads us to concur with Dr Leese that thromboembolism is an important complication in acute polyneuritis and that its frequency justifies active measures to prevent it. One of these preventive measures is low-dose subcutaneous heparin. As Dr Leese points out, the evidence in favour of its safety and effectiveness is accumulating.

Charles P Bredin

J DONALD BALL W H MORTON

\begin{abstract}
Assisted Respiration Unit,
\end{abstract}
Llandough Hospital,
Penarth, Glam

\section{Tubal pregnancy and surgery}

SIR,-The hypothesis that removal of the ipsilateral ovary at salpingectomy for ectopic gestation would assist subsequent fertility was propounded by Sir Norman Jeffcoate in 1955. ${ }^{1}$ I have been told by one of his former assistants that Sir Norman in fact never performed this manoeuvre himself-but perhaps "best evidence" will be forthcoming on this point. It took nine years before the hypothesis was categorically disproved by Abrams and Farrell. ${ }^{2}$ These authors drew on reports from six internationally famous medical centres, including Liverpool, and found that of 238 patients with tubal pregnancies $46 \%$ subsequently conceived after salpingectomy alone while $43 \%$ conceived after salpingooophorectomy. In the interim a great many women lost their ovaries fruitlessly. Unfortunately, the initial proposition was for a time carried from textbook to textbook without the refutation and took years to die out completely, although subsequent studies ${ }^{3} 4$ confirmed Abrams and Farrell's conclusions that oophorectomy does not improve the prognosis for successful pregnancy.

In your leading article (13 March, p 607) you seem to have been stimulated to resurrect this dead issue by an unjustified extrapolation by Professor J S Scott and his colleagues (13 March, p 631). Elective tubal surgery for chronic pelvic inflammatory disease is a different situation from that of acute ectopic gestation, and Professor Scott's series did not contain a single case of the latter. You talk of logic-surely the premises should be questioned when the conclusion conflicts with the facts? It is unfortunate that the process of transperitoneal migration of the ovum appears difficult to those with a "dissecting board" concept of the pelvic organs. In life the ovaries are seldom more than 3 or $4 \mathrm{~cm}$ apart and it is likely that-as the limerick has it-"in stormy weather they bang together."

\section{F HaWkins}

\section{Institute of Obstetrics and \\ Gynaecology,
Hammersmith Hospital \\ London W 12}

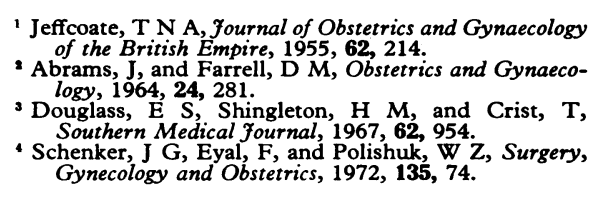

' Jeffcoate, T N A, Journal of Obstetrics and Gynaecology
of the British Empire, $1955,62,214$.
' Abrams, J, and Farrell, D M, Obstetrics and Gynaeco-
logy, 1964, 24, 281.
' Douglass, E S, Shingleton, H M, and Crist, T,
Southern Medical fournal, 1967, 62, 954.
' Schenker, J G, Eyal, F, and Polishuk, W Z, Surgery,
Gynecology and Obstetrics, 1972, 135, 74.

\section{Rectal loss of vaginal vibrators}

SIR,-I read with interest the article by Dr J S Haft and others (13 March, p 626), concerning the loss and retrieval of two vaginal vibrators. The use of these objects for anal gratification during sexual intercourse is interesting, and the authors were fortunate in having a clear history before they started treatment.

A 37-year-old single man presented with the complaint that some youths had attacked him and thrust a bottle up his anus 3 days before. Plain $x$-ray, showing the shadow of what turned out to be a vaginal vibrator lying within the pelvis, caused initial confusion. The patient was given a general anaesthetic with muscle relaxation and put into the lithotomy position. The anus was dilated and a Parks retractor inserted. The vibrator was pushed into view from the upper rectum and recovered with the fingers, it being impossible to grasp the object with the forceps then available.

A clear history cannot always be obtained in cases of this kind, especially where the vibrator is self-introduced. General anaesthesia with muscle relaxation is to be recommended so that the vibrator can be more easily pushed downwards by suprapubic pressure and also in case a formal laparotomy becomes necessary.

The authors' comments about changes in design, not only to prevent initial loss but to aid subsequent recovery, are appropriate. The consequences of misuse, however, should be included in courses of medical rather than sex education, but a change of design enforced by law would make both unnecessary.

Sefton General Hospital,

W K MOORES

Siverpool

SIR,-Dr J S Haft and his colleagues (13 March, p 626) very properly stress the hazards of vaginal vibrators lost in the rectum. I feel their two patients were likely to be atypical in that both were heterosexual females. In 1973 I reported ${ }^{1}$ two cases of young homosexual males in the same predicament and have since seen one more. This occurred in a 24-year-old Asian male indulging in nala masturbation who presented two days after loss of the vibrator. The instrument was lodged high in the curve of the sacrum and easily removed bimanually under light general anaesthesia. The lax anus of these homosexuals allows a comparatively easy delivery of these instruments. $\mathrm{My}$ two previous patients presented early with the curious physical sign of a vibrating umbilicus.

Wexham Park Hospital,

BRYAN MaYOU Slough, Bucks 1 Jackson, D, and Mayou, B J, British Medical fournal,
1973, 2, 780.

SiR.-There is a well-known cautionary tale about the trials of a mother who remembered to tell her children everything, even "not to put beans up their noses."

I would recommend consideration of this tale to any school medical officer tempted to follow the advice given by $\mathrm{Dr} \mathrm{J} S \mathrm{Haft}$ and his colleagues (13 March, p 626) to include warnings against the improper use of vaginal vibrators in sex education programmes. I feel strongly that such advice is bound to cause more problems rather than less.

Cheltenham

ANN G MORGAN

Position of myocardial infarct and results of alprenolol treatment

SIR,-Two studies ${ }^{12}$ have recently shown that sudden deaths after myocardial infarction can be reduced by long-term treatment with alprenolol and a multicentre international study (27 September, p 735) has shown similar results with practolol therapy. The authors of the latter study recommend longterm practolol therapy during the postinfarction phase, especially for patients with anterior-wall infarcts. Vedin et $^{a l^{2}}$ were unable to find in their study that the effect of chronic beta-blockade depended on the position of the infarct.

Since this question is of clinical importance we wish to record some additional information and comments concerning our study ${ }^{1}$ (in which we found a reduction in the number of sudden deaths and reinfarctions in the group treated with alprenolol during a two-year follow-up period). We found that $48 \%$ of the patients had anterior infarcts and $52 \%$ posterior infarcts and there was no significant difference in this distribution between the alprenolol and the control group. The reduction in the number of sudden deaths in the alprenolol group was independent of the position of the infarct. The incidence of reinfarction in the alprenolol group was $6 \%(10 \%$ of patients with anterior and $3 \%$ of those with posterior infarcts-not significant) and in the control group $16 \%$ (equal for patients with anterior and those with posterior infarcts). We were unable to determine whether the patients with anterior infarcts in the control group developed tachyarrhythmias more frequently than those in the alprenolol group.

Thus we have been unable to find any dependence of the reduction in sudden deaths and reinfarctions during long-term treatment with alprenolol after myocardial infarction on the position of the infarct.

Gösta AHLMARK HeLge SAETRE

Medical Department,

Falu Hospital,

1 Ahlmark, G, Saetre, H, and Korsgren, M, Lancet, $1974,2,1563$. Vedin, A, Wilhelmsson, C, and Werkö, L, Acta
Medica Scandinavica, 1975, suppl 575, p 1. 